\title{
The Disclosure of Direct-to-Consumer Genetic Testing: Sounding Out the Psychological Perspective of Consumers
}

\section{Serena Oliveri ${ }^{1,2^{*}}$ and Gabriella Pravettoni ${ }^{1,2}$}

${ }^{1}$ Interdisciplinary Research Center on Decision Making Processes IRIDe, Department of Oncology and Hematoncology, University of Milan, Via Festa del Perdono 7, 20122 Milan, Italy

${ }^{2}$ Applied Research Division for Cognitive and Psychological Science, IEO European Institute of Oncology, via Ripamonti 435, 20141 Milan, Italy

*Corresponding author: Serena Oliveri, Applied Research Unit for Cognitive and Psychological Science, European Institute of Oncology, Via Ripamonti 435, 20141 Milan, Italy, Tel: + 39 0257489731; E-mail: serena.oliveri@unimi.it

Received date: June 10, 2016; Accepted date: July 21, 2016; Published date: July 27, 2016

Copyright: ( 2016 Oliveri S, et al. This is an open-access article distributed under the terms of the Creative Commons Attribution License, which permits unrestricted use, distribution and reproduction in any medium, provided the original author and source are credited.

\section{List of Abbreviations:}

DTC: Direct-to-Consumer; FDA: Food and Drug Administration; DTC-GC: Direct-to-Consumer Genetic Service

\section{Commentary}

Medicine is increasingly conceived as tailoring to the needs of each individual. Progress in this area comes, for instance, in the wake of human genetic testing, which intends to "profile" patients' genetic predisposition towards specific diseases, promoting early and personalized interventions. This aspect is a fundamental component of the so-called pre-emptive approach [1].

In implementing genetic testing on a larger scale, there is a need to understand who the consumer of genetic testing really is. One must therefore consider the uniqueness of every individual's psychological, social, cognitive and behavioral profiles. According to these premises, we assume that having information about the consumers' psychosocial-cognitive state would help healthcare professionals and policy makers to find effective strategies that can be employed to successfully interact with consumers, and thereby strive to really enhance individual empowerment and shared decision making [2-4].

\section{The transition from patient to consumer}

Initially, genetic testing was provided only by specialized institutions, as a part of clinical and research studies and within a network of experienced professionals. The search by scientists for disease-linked genes began by studying DNA samples from disease families, i.e. families in which numerous relatives, over several generations, had developed the illness. Therefore, those who underwent this type of screening were people with a family history of disease.

Since the early 1980s, several private companies have been offering personalized medicine genetic testing to the public. Their perspective is not in the sale of the test (sometimes inexpensive at around \$99) but rather in the creation of a DNA database of patients/citizens for the development of new treatments and new genetic tests. The 23andMe web page (the most popular genetic company in US) expressed it thus: "getting involved in a new way of doing research [...] with enough data, we believe can produce revolutionary findings that will benefit us all" (https://www.23andme.com/research/). Advertisements tend to highlight the benefits and minimize any possible limitations $[5,6]$. Companies offering DTC genetic tests employ highly aggressive marketing strategies, in which they explain that the data could be used: "to shed light on your ancestors, your family and, above all, on yourself", to understand the most suitable diet or lifestyle for each person, to understand how one's body reacts to nicotine for instance, or to put you in possession of "information to share with your family and friends" $[7,8]$. Genetic testing comes as a simple tool to acquire personal information, independent of the purpose for which it will be used.

In the outlined scenario, each individual, although not a professional researcher, can exercise the freedom to participate in scientific research, and at the same time can make available his/her genetic heritage, drawing an immediate advantage (e.g. gathering info about a condition from which he/she suffers). Consumers choose to be engaged in the biotechnology research field to use genetic analysis results for the protection of their own health [9].

The exploitation of the potentiality of genetic testing has led to the emergence of a category of consumers that medical science has termed "unpatients". These are healthy people who show predispositions, at the genotypic level, concerning the onset of certain diseases whose genetic matrix is properly known [10].

Nevertheless, diseases caused by a single gene usually do not present any problems in interpreting risk probability, while common-complex disorders such as heart diseases, diabetes, arthritis, cancer and psychiatric disorders are usually the result of variation in many genes, each contributing to a small amount of genetic susceptibility, acting in concert with environmental or epigenetic factors $[11,12]$. In this case, tests present serious problems of interpretation because genes play a limited role (usually from $5 \%$ to $20 \%$ of the risk). Many genes can only increase susceptibility to disease development but they do not represent a certainty or a "sentence to disease".

Unsure about which is better to choose and how much (if any) trust to place in such services, consumers choose to consult several companies, aiming to gain greater certainty about the result. However, the analyses provided by DTC companies do not plumb the entire genome. The "variable" points in DNA number millions throughout the genome, dozens in a single gene. It is sufficient that companies opt for different ones, although related to the same disease, to achieve radically different results. Moreover, consumers purchase tests without the obligatory involvement of the healthcare providers, leaving the consumers free to make their own interpretation and manage their genetic risk data. A free market of choices detached from a medical and therapeutic context takes shape [13]. 


\section{The importance of being a consumer}

It has been argued that tests may even cause psychological harm to consumers, since they provide complicated and potentially unreliable data, leaving people vulnerable to inappropriate health decisions $[6,14]$. A perceived high risk of disease may increase anxiety and a low risk may discourage healthy behavior $[15,16]$. Nevertheless, a recent review [17] concluded there was no evidence of harm by DTC genetic tests. The largest study on DTC genetic tests [18] found no significant difference in anxiety levels before testing, after testing and 3 months later, and no increase in the subsequent use of additional screening tests associated with the results of the DTC. Another study [19] found no significant changes in habits except for those regarding physician consultation. Concerning the profile of consumers, the literature shows that people who spontaneously decide to buy a genomic test are more likely to be "information seekers" [20], and we could infer that they might be "anxious" about their health and "anxious" to know. Indeed seeking information might serve both to reduce distress and to take concrete action against the risk [21,22]. Despite these inferences, the literature also shows that being an information seeker and being more informed about advances in genetics may be predictive of one's deciding on taking up genomic tests but not predictive of a concrete use of this information $[20,23,24]$. Consumers collect information which they then do not use, or at least they do not use the way we expect (change of habits, quality of life, screening etc.) [25]. The core issue is that if people do not believe that knowing more about a health condition, such as a genetic condition, will allow them to act something (to do something and face the condition), then they are not persuaded to effectively use this knowledge [26].

Hence, we need a comprehensive examination of "who are these consumers?" [27].

The last few years of scientific and policy debate on direct-toconsumer genetic testing culminated in a series of studies indicating that, contrary to initial intuitive expectations, people are substantially resilient to the long-term consequences of positive results to genetic testing [28]. A little anxiety, when a health-related outcome is identified, is an almost predictable index to something unknown because people have to face the uncertainty of the onset of a disease [29], the possibility of passing the faulty gene on to their children, and the potential for genetic discrimination. However, we suggest that nonclinical anxiety can be considered as a precursor of patients' health engagement and behavioral change, but only in the light of other complex cognitive and emotional mechanisms whose investigation in genetic risk is of paramount importance [29].

Both emotional and cognitive factors affect people's resilience to gene test results [30-32]. Ho et al. [33] demonstrated that people who undergo HCRC (hereditary colorectal cancer) genetic testing and have a high level of hopefulness would have a higher tendency to show a resilience outcome trajectory pattern than their low-hope counterparts. A mindful and accepting orientation toward experience may facilitate psychological resilience in response to negative outcomes and illness [34,35]. Predictors of resilience include personality characteristics, positive or negative personal and family experiences [29] and being flexible in the coping strategies used.

Moreover, we need to take into account the fact that consumers' attitudes towards genetic testing differ by country, based on cultural differences, and are related to individual characteristics such as age, gender and educational level [36,37]. People are more worried about privacy and discrimination problems in the USA and northern Europe [38-40], whereas they are more concerned about the influence such tests may have on future plans and on their reliability in southern Europe $[37,41,42]$. Younger people have a higher level of interest in genetic testing and DTCGT, along with a higher attitude towards new health technologies in general [43].

According to all these evidences, we argue that future studies on direct-to-consumer genetic testing should provide a rich conceptual framework about the worries and concerns that consumers may feel about genetic testing, and identify their psycho-emotional profiles and health-related behaviors. In this way we would hope to obtain a clearer picture of their different interests perceptions of genetic risk. We furthermore suggest the implementation of a longitudinal perspective, with regular follow-up assessments to empirically measure how consumers' experiences, perceptions, attitudes and preferences regarding risk communication change over time [39].

\section{Perception of risk, uncertainty, and responsibility}

Risk is linked to the knowledge of the probability of possible outcomes, whereas in a state of uncertainty the probability of an event is unknown. However, in medical contexts the term "risk" is often used even when probabilities are unknown and the distinction between risk and uncertainty becomes unclear. DTC is such a case.

The introduction of DTC genetic information raises questions on risk communication, health responsibility, and management of the gap between risks and lack of therapeutic options. Typically, decisions about appropriate risk levels for genetic information are decided by expert committees [13]. There is an almost unanimous belief that the spread of this kind of information is justified only if there is a useful way to pre-emptively react (e.g. when therapeutic effectiveness is mainly linked to an early diagnosis and genetic results are able to ensure a susceptibility diagnosis for curable disease).

Nevertheless, although for many genetic conditions (e.g. Alzheimer or Huntington disease) there are no effective therapies or unproven therapies (whose effectiveness and safety have yet to be demonstrated), the results of a genetic test, even if unfavorable, may have salient personal implications, since such results could influence reproductive decisions, decisions on family planning and on life planning in general. The utility of a genetic test cannot therefore be assessed by the sole criterion of its medical implications, but one should also consider the broader implications involving aspects of the life of the consumer, who should receive full information on the meaning of the genetic investigation and who should have the space for an independent evaluation.

We should strive to truly enhance individual empowerment and shared decision making and promote a model that is not opposed to the implementation of DTC genetic testing but imposes informational commitments to the companies which offer them (Figure 1). 


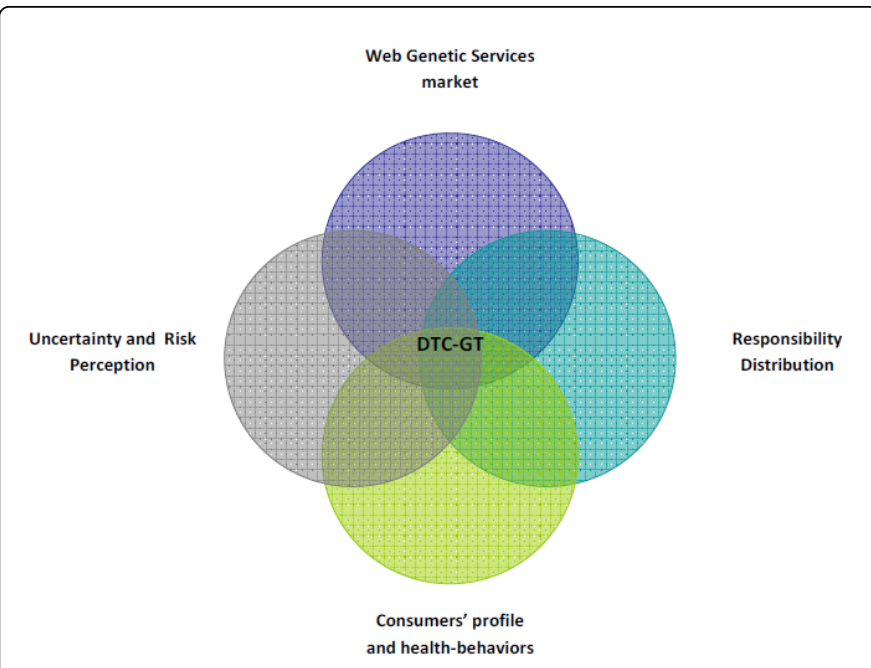

Figure 1: Philosophical, social and ethical challenges of Direct-toConsumer Genetic Testing. Web availability of genetic information and DTC services, without the involvement of health care professionals, associated with the informational richness, complexity and frequently uncertain meaning of these data, have generated a range of concerns about the ethical management of genomic information. Important issues about the concept of risk, uncertainty and responsibility distribution between the healthcare system and consumer arise. In this framework the psychobehavioural identikit of the consumer plays a crucial role in policy regulation.

\section{Competing Interests:}

The authors declare no competing interests.

\section{Acknowledgements}

The research for this paper was made possible by a grant to the project "Mind the Risk", from The Swedish Foundation for Humanities and Social Sciences. The foundation had no influence on the writings and conclusions. We thank William Russell-Edu, BSc, for his assistance in proofreading the manuscript.

\section{References}

1. Imura H (2013) Life course health care and preemptive approach to noncommunicable diseases. Proc Jpn Acad Ser B Phys Biol Sci 89: 462-473.

2. Riva S, Monti M, Iannello P, Pravettoni G, Schulz PJ, et al. (2014) A Preliminary Mixed-Method Investigation of Trust and Hidden Signals in Medical Consultations. PLos ONE 9: e90941.

3. Gorini A, Pravettoni G (2011) An overview on cognitive aspects implicated in medical decisions. Eur J Intern Med 22: 547-553.

4. Riva S, Monti M, Iannello P, Antonietti A (2012) The Representation of Risk in Routine Medical Experience: What Actions for Contemporary Health Policy? PLoS ONE 7: e48297.

5. Singleton A, Hamby Erby L, Foisie KV, Kaphingst K (2012) Informed choice in direct-to-consumer genetic testing (DTCGT) websites: a content analysis of benefits, risks, and limitations. J Genet Couns 21: 433439.

6. Lachance CR, Erby LAH, Ford BM, Allen VC Jr, Kaphingst KA (2010) Informational content, literacy demands, and usability of websites offering health-related genetic tests directly to consumers. Genet Med 12: 304-12.

7. Kaye J (2008) The regulation of direct-to-consumer genetic tests. Hum Mol Gen 17: R180-R183.

8. Masiero M, Riva S, Fioretti C, Pravettoni G (2016) Pediatric Blood Cancer Survivors and Tobacco Use across Adolescence and Emerging Adulthood: A Narrative Review. Frontiers in psychology 7.

9. Prainsack B (2011) Voting with their mice: personal genome testing and the "participatory turn" in disease research. Account Res 18: 132-147.

10. Jonsen AR, Durfy SJ, Burke W, Motusky AG (1996) The Advent of the "Unpatients". Nat Med 2: 622-624.

11. Cittaro D, Lampis V, Luchetti A, Coccurello R, Guffanti A, et al. (2016) Histone Modifications in a Mouse Model of Early Adversities and Panic Disorder: Role for Asic1 and Neurodevelopmental Genes. Sci Rep 6.

12. Relton CL, Smith GD (2010) Epigenetic epidemiology of common complex disease: prospects for prediction, prevention, and treatment. PLoS Med 7: e1000356.

13. Oliveri S, Pravettoni G, Fioretti C, Hansson MG (2016) Let the Individuals Directly Concerned Decide: a solution to tragic choices in genetic risk information. Public Health Genomics 19: 307-313.

14. Kaufman DJ, Bollinger JM, Dvoskin RL, Scott JA (2012) Risky business: risk perception and the use of medical services among customers of DTC personal genetic testing. J Genet Couns 21: 413-422.

15. Nordin K, Liden A, Hansson M, Rosenquist R, Berglund G et al. (2002) Coping style, psychological distress, risk perception, and satisfaction in subjects attending genetic counselling for hereditary cancer. J Med Gen 39: 689-694

16. Samuel GN, Jordens CFC, Kerridge I (2010) Direct-to-consumer personal genome testing: ethical and regulatory issues that arise from wanting to 'know' your DNA. Internal Med 40: 220-224.

17. McBride CM, Wade CH, Kaphingst KA (2010) Consumers' views of direct-to-consumer genetic information. Annu Rev Genomics Hum Genet 22: 427-446.

18. Bloss CS, Ornowski L, Silver E, Cargill M, Vanier V, et al. (2010) Consumer perceptions of direct-to-consumer personalized genomic risk assessments. Genet Med 12: 556-566.

19. Bloss CS, Schork NJ, Topol EJ (2014) Direct-to-consumer pharmacogenomic testing is associated with increased physician utilisation. J Med Genet 51: 83-9.

20. McBride CM, Alford SH, Reid RJ, Larson EB, Baxevanis AD, et al. (2009) Characteristics of users of online personalized genomic risk assessments: implications for physician-patient interactions. Genet Med 11: 582-587.

21. Lazarus RS, Folkman S (1984) Coping and adaptation. In: Gentry WD (ed.) The handbook of behavioral medicine. Guilford, New York.

22. Folkman SJ (1984) Personal control and stress and coping processes: a theoretical analysis. J Pers Soc Psychol 46: 839-852.

23. Bloss CS, Madlensky L, Schork NJ, Topol EJ (2011) Genomic information as a behavioral health intervention: can it work?. Per Med 8: 659-667.

24. Heshka JT, Palleschi C, Howley H, Wilson B, Wells PS (2008) A systematic review of perceived risks, psychological and behavioral impacts of genetic testing. Genet Med 10: 19-32.

25. Gorini A, Pravettoni G (2016) Why do we pay for information that we won't use\&quest; A cognitive-based explanation for genetic information seeking. Eur J Hum Genet 24: 625.

26. Case DO, Andrews JE, Johnson JD, Allard SL (2005) Avoiding versus seeking: the relationship of information seeking to avoidance, blunting, coping, dissonance, and related concepts. J Med Libr Assoc 93: 353.

27. Oliveri S, Renzi C, Pravettonia G (2015) Toward an in-depth profiling of DTC users. Clin Genet 88: 505-506.

28. Farahany NA (2014) Regulation: The FDA is overcautious on consumer genomics. Nature 505: 286-287.

29. Oliveri S, Renzi C, Masiero M, Pravettoni G (2015) Living at risk: factors that affect the experience of direct-to-consumer genetic testing. Mayo Clin Proc 90: 1323-1326. 
Citation: Oliveri S, Pravettoni G (2016) The Disclosure of Direct-to-Consumer Genetic Testing: Sounding Out the Psychological Perspective of Consumers. Biol Med (Aligarh) 8: 316. doi:10.4172/0974-8369.1000316

Page 4 of 4

30. Michie S, Bobrow M, Marteau TM (2001) Predictive genetic testing in children and adults: a study of emotional impact. J Med Genet 38 : 519-526.

31. Lopez SJ, Snyder CR (2003) Positive psychological assessment. A handbook of models and measures. American Psychological Association, Washington D.C.

32. Kumpfer KL. Factors and processes contributing to resilience. In Resilience and development. 2002, Springer US: pp. 179-224.

33. Ho SM, Ho JW, Bonanno GA, Chu AT, Chan EM (2010) Hopefulness predicts resilience after hereditary colorectal cancer genetic testing: a prospective outcome trajectories study. BMC cancer 10: 279.

34. Rutter M (2012) Resilience as a dynamic concept. Dev Psychopathol 24: 335-344.

35. Fioretti C, Smorti A (2016) Narrating positive versus negative memories of illness: Does narrating influence the availability and the emotional involvement of memories of illness? Eur J Cancer Care [Epub ahead of print].

36. Henneman L, Timmermans DR, Wal GVD (2006) Public attitudes toward genetic testing: perceived benefits and objections. Genet Test 10: 139-145.

37. Aro AR, Hakonen A, Hietala M, Lönnqvist J, Niemelä P, et al. (1997) Acceptance of genetic testing in a general population: age, education and gender differences. Patient education and counseling 32: 41-49.
38. Ormond KE, Hudgins L, Ladd JM, Magnus DM, Greely HT, et al. (2011) Medical and graduate students' attitudes toward personal genomics. Genet Med 13: 400-408.

39. Henneman L, Vermeulen E, van El CG, Claassen L, Timmermans DR, et al. (2013) Public attitudes towards genetic testing revisited: comparing opinions between 2002 and 2010. Eur J Human Genet 21: 793-799.

40. Hietala M, Hakonen A, Aro AR, Niemelä P, Peltonen L, et al. (1995) Attitudes toward genetic testing among the general population and relatives of patients with a severe genetic disease: a survey from Finland. Am J Hum Genet 56: 1493-500.

41. Vayena E, Ineichen C, Stoupka E, Hafen E (2014) Playing a part in research? University students' attitudes to direct-to-consumer genomics. Public health genomics 17: 158-168.

42. Jallinoja P, Hakonen A, Aro AR, Niemelä P, Hietala M, et al. (1998) Attitudes towards genetic testing: analysis of contradictions. Soc Sci Med 46: $1367-1374$

43. Gaskell G, Allum N, Bauer M, Durant J, Allansdottir A, et al. (2000) Biotechnology and the European public. Nat Biotech 18: 935-938. 